\title{
Phacoemulsification combined with deep sclerectomy augmented with mitomycin and amniotic membrane implantation in chronic primary open angle glaucoma with cataract
}

Hazem Helmy

Lecturer of Ophthalmology, Glaucoma and Optic Nerve Diseases Department, Glaucoma Unit, Research Institute of Ophthalmology, Egypt

\section{Type of article: Original}

\begin{abstract}
Objective: The aim of this study was to determine the safety and efficacy of combined phacoemulsification plus Intraocular lens (IOL) implantation with deep sclerectomy augmented with mitomycin C (MMC) and sub-flap implantation of amniotic membrane for the management of uncontrolled, chronic, primary open-angle glaucoma patients.

Methods: This prospective study included 41 patients with chronic, primary, open-angle glaucoma and cataract uncontrolled with medical treatment who underwent combined phacoemulsification augmented with mitomycin $\mathrm{C}$ (MMC) application and amniotic membrane implantation under the scleral flap. Intraocular pressure (IOP), visual acuity, glaucoma medications, stabilization of visual field, complications, and viability of the success rate were assessed a 36-month follow-up period.

Results: The mean age of cases was $54.8 \pm 5.3$ years. Sixty-one percent of cases were males, and $39 \%$ were females. The mean IOP decreased from $23.8 \pm 1.8 \mathrm{mmHg}$ preoperatively to $16.8 \pm 2.3 \mathrm{mmHg}$ postoperatively. The overall success rate was $97.5,95$, and $92.7 \%$ in the first, second, and third year, respectively. The overall success rate was $90 \%$ in the first year, but that decreased to 85.3 and $78 \%$ in the second and third year, respectively. Qualified success was 7.5, 10, and $14.7 \%$ in the first, second, and third year, respectively. Failure was recorded as $2.5,5$, and $7.3 \%$ in the first, second, and third year, respectively. IOP reduction was sustained through the follow-up period. Visual acuity improved from $0.13 \pm 0.06$ to $0.9 \pm 0.07$ ( $\mathrm{p}<0.001)$. The visual field improved significantly in the first assessment, from $14.0 \pm 2.7$ preoperatively to $12.6 \pm 2.6$ at three months postoperatively $(\mathrm{p}<0.001)$, after which it became stable for the remainder of the follow-up period. One hundred percent of cases were on three anti-glaucoma drugs preoperatively, while postoperatively, $12.2 \%$ were on three drugs, $4.2 \%$ were on two drugs, and $82.9 \%$ were controlled without anti-glaucoma treatment. There were minor postoperative complications all of which were minor, such as a spike in the post-operative IOP and the formation of fibrinous material in the anterior chamber, both of which were treated medically without any adverse effects on the final results.

Conclusion: Amniotic membrane implantation in conjunction with $\mathrm{MMC}$ application may be an effective alternative to expensive implants in deep sclerectomy combined with phacoemulsification, and this approach can be used safely in advanced cases.

Keywords: phacoemulsification, amniotic membrane implantation, $\mathrm{MMC}$ application, intraocular pressure, deep sclerectomy, non-penetrating glaucoma surgery
\end{abstract}

\section{Introduction}

Cataracts and glaucoma are the most prevalent causes of blindness in old age all over the world (1). The combination of cataract extraction and glaucoma surgery has become popular among surgeons for the treatment of coexisting cataracts and glaucoma (2-4). In advanced glaucoma, glaucoma surgery carries a 6-13\% risk of snuff out and wipe out syndrome, most probably due to hypotony (5). Non-penetrating, deep sclerectomy achieves surgical

\section{Corresponding author:}

Dr. Hazem Helmy, Glaucoma and Optic Nerve Diseases Department, Glaucoma Unit, Research Institute of Ophthalmology, Egypt. E-mail: hazem.helmy@yahoo.com

Received: January 06, 2016, Accepted: March 06, 2016, Published: April 2016

iThenticate screening: March 06, 2016, English editing: March 12, 2016, Quality control: March 16, 2016

(C) 2016 The Authors. This is an open access article under the terms of the Creative Commons Attribution-NonCommercialNoDerivs License, which permits use and distribution in any medium, provided the original work is properly cited, the use is non-commercial and no modifications or adaptations are made. 
control of Intraocular pressure (IOP) by enhancing drainage of aqueous fluids preserving the trabecular endothelial layer, which decreases the incidence of hyphema, hypotony, choroidal detachment, and anterior chamber inflammation (6-8). Opening Schlemm's canal in addition to the creation of Trabeculo-Descemet's window and inner wall peeling of Schlemm's canal often are associated with multiple micro perforations in the juxta-canalicular meshwork that facilitate a slow aqueous outflow. Creating this space, in addition to the creation of intra scleral space, increases filtration area both at the time of surgery and permanently over time. This also introduces an additional route of filtration, such as Schlemm's canal and ciliary body (9). Non-penetrating glaucoma surgery (NPGS) has undergone a series of changes that improved the results, such as devices that prevent the formation of scars between the remaining superficial flap and the scleral bed. It maintains the intra-scleral lack of aqueous humor that was formed by removal of the deep sclero-corneal fragment, which increases the success rate and subsequently decreases the need for postoperative glaucoma treatment $(10,11)$. Absorbable implants include purified porcinederived collagen due to its ability to expand its volume when it comes in contact with the aqueous humor. Another implant is reticulated hyaluronic acid pieces, which occupies a large volume in the filtering area and allows sufficient circulation of the aqueous humor. As the use of implants under the scleral flap necessarily makes the surgery more expensive, many glaucoma surgeons have tried to use cheaper alternatives, such as a piece of chromic suture material, autologous sclera, high viscosity viscoelastics, or amniotic membrane $(12,13)$. Mitomycin C $(\mathrm{MMC})$ was used as an adjunctive treatment to the filtration lake by decreasing the incidence of healing between the scleral flap and the surrounding scleral bed (14-17).

Management of glaucoma with a coexisting cataract is controversial, but cataract surgery in primarily open-angle glaucoma patients helps significantly in the follow-up performance in addition to improvement of visual acuity. The presence of a cataract affects the reliability of OCT measurements (18) as well as the perimeter (19). The efficacy and safety of phacoemulsification combined with non-penetrating deep sclerectomy as a surgical option for these patients has been presented in many studies (20-23). The aim of this study was to determine the advantage of the implantation of an amniotic membrane in addition to using MMC in improving the surgical outcome of combined phacoemulsification with deep sclerectomy without need for expensive devices and implants in addition to the avoidance of complications of trabeculectomy that may be a serious concern in uncontrolled, advanced glaucoma cases.

\section{Material and Methods}

\subsection{Research design and setting}

This is a prospective, randomized, clinical trial comprised 41 eyes of 41 patients (one eye per patient) of chronic primary open angle glaucoma with coexisting cataract and uncontrolled with medical treatment and cataract having an indication for surgery. Uncontrolled cases include cases without satisfying intraocular pressure (IOP) control ( $\geqslant$ $21 \mathrm{mmHg}$ ) despite maximally tolerated medications or with progression of visual field. All cases were collected from the Glaucoma Clinic in the Research Institute of Ophthalmology during 2012-2013.

\subsection{Diagnosis}

The criteria for diagnosis of primary, open-angle glaucoma was IOP $>21 \mathrm{mmHG}$ without anti-glaucoma medication, enlarged cup disc ratio (vertical diameter), visual field changes (detected by Humphrey visual field analyzer), retinal nerve fiber layer defects (detected by slit-lamp bio-microscopy in addition to OCT examination); all of these parameters were compatible with glaucomatous changes. Patients underwent phacoemulsification and foldable IOL implantation combined with deep sclerectomy augmented with MMC application in addition to amniotic membrane implantation under the scleral flap. IOP was measured using Goldmann applanation tonometry by the same observer. Two values were assessed, and the mean value was used for analysis. If the two values differed by more than 2 points, a third one was obtained, and the median was chosen. Gonioscopy was performed using a Zeiss-style 4-mirror gonioscopic lens (model OPDSG, Ocular Instruments, Inc. USA). Anterior chamber angle grading of 3 or more according to the Shaffer grading scale in all quadrants was required to be eligible for the study. All cases underwent a full ophthalmological examination, including pre- and post-operative best corrected visual acuity (BCVA) measurement using the Log MAR scale, slit lamp examination of anterior segment, anterior chamber examination, grade of cataract, fundus examination by slit lamp bio-microscopy using $+90 \mathrm{D}$ lens for examination of the head of the optic nerve. B Scan ultrasonography was done in case of inadequate visualization. Examination of the visual field was done using the Swedish Interactive Threshold Algorithm (SITA) standard (24) Humphery visual field analyzer (745i-Carl Zeiss Meditech, AG, Jena-Germany), Retinal nerve fiber bundle layer thickness was examined with Fourier domain RTVue -100 OCT machine OCT (Optovue, Inc. Fermont, CA, USA) also were performed if adequate clarity of the media permitted. 


\subsection{Exclusion criteria}

Exclusion criteria included all cases with history of glaucoma surgery, narrow angle, primary or secondary angle closure glaucoma, other cases with open angle glaucoma except primary open angle glaucoma, such as pseudoexfoliaton, uveitic and steroid induced glaucoma in addition to cases with corneal opacity that might interfere with the perfection of the phacoemulsification procedure.

\subsection{Postoperative follow up schedule}

All patients underwent measurement of log MAR best corrected visual acuity (BCVA), UBM (UBM,840 ZeissHumphery Medical Instruments, $50 \mathrm{MHz}$ ) examination of the thickness of scleral pocket at 6 and 12 months, visual field examination after three months and then every 6 months for 36 months, IOP measurements at 1,3,6 months and then every 6 months for 36 months.

\subsection{Surgical technique:}

All operative cases were done by the same surgeon. Surgery was performed under local anesthesia using $0.5 \%$ tetracaine hydrochloride:

\subsubsection{Phacoemulsification:}

consisted of a 2.2-mm, 3-step clear corneal incision fashioned in the upper temporal quadrant of the limbus away from the deep sclerectomy site, followed by two angled side ports, and $\mathrm{AC}$ was inflated with soft shell viscoelastic technique (Healon and methylcellulose). Continuous curvilinear capsulorhexis ( $\mathrm{CCC}$ ) was done using a cystitome followed by hydro-dissection and hydro-delineation, in the bag phacoemulsification using the divide and conquer technique, cortical aspiration, and insertion of foldable acrylic IOL in the capsular bag were performed. All cases that developed surgical complications were excluded from the study.

\subsubsection{Deep sclerectomy:}

The globe was immobilized with a 4-0 nylon suture beneath the tendon of the superior rectus muscle preplaced before starting phacoemulsification. A fornix-based conjunctival periotomy of 5-6 $\mathrm{mm}$ was fashioned at the 12 o'clock position of the superior limbus using blunt dissection. A $5 \times 5$ partial thickness scleral flap (one third to one half of the scleral thickness) was fashioned and dissected $1.0 \mathrm{~mm}$ in clear cornea using a crescent blade. A cellulose sponge soaked with MMC $0.4 \mathrm{mg} / \mathrm{ml}$ (Mitomycin $10 \mathrm{mg}$, Kyowa Hakko Kogyo Co., Ltd., Tokyo, Japan) was applied over the scleral bed under tenon's capsule and two applied under the scleral flap for three minutes, then vigorous irrigation with saline was done. The deep flap borders were outlined $1.0 \mathrm{~mm}$ within the edge of the superficial flap and up to $90 \%$ of the scleral thickness using a super blade no. 15 . The deep flap was fashioned and dissected anteriorly over Descemet's membrane. Whenever trabeculo-descemet's perforation occurred during dissection, guarded trabeculectomy was done, and the patient was excluded from the study. The deep scleral flap was excised using super blade no. 15. Schlemm's canal was de-roofed with blunt micro-forceps. Preserved freezedried (lyophilized) amniotic membrane with its epithelial side up was implanted between the scleral flap and scleral bed and fixed to the sclera by 10/0 nylon sutures, one at each corner. The scleral flap was closed with 10/0 nylon sutures, one in each quadrant. The conjunctiva were closed with $8 / 0$ a polyglactin continuous suture.

\subsection{Postoperative medications}

Postoperative medications included $0.3 \%$ gatifloxacin four times daily for three weeks and $1 \%$ predinsolone acetate six times daily as an initial dose that was tapered gradually over one month, depending on the degree of postoperative inflammation. Goniopuncture with an ND: YAG laser was done when the filtration was insufficient, preventing achievement of the target IOP and/or the bleb was shallow. Gonioscopy contact lens was used for goniopuncture, which was done one to three months postoperatively.

\subsection{Success criteria}

Success was defined as $5>$ IOP $<21 \mathrm{mmHg}$ with or without anti-glaucoma treatment. Complete success was defined as $10>$ IOP $<21$ without anti-glaucoma treatment. Qualified success was defined as IOP greater than 5 $\mathrm{mmHg}$ and less than $21 \mathrm{mmHg}$ with medications. Failure was defined as IOP less than $5 \mathrm{mmHg}$ or more than 21 $\mathrm{mm} \mathrm{Hg}$ using every available glaucoma medication that the patient could topically or systemically tolerate (maximal tolerated medical therapy). All procedures and follow-up visits were done at the Research Institute of Ophthalmology (R.I.O.) in the Ministry of Scientific Research in Egypt. The study was performed in accordance with the tenets of the Declaration of Helsinki of 1975 (1983 revision). The Research Committee of the Research Institute of Ophthalmology approved the protocol of the study. All patients received a thorough explanation of the procedures to be used in the study, and they signed an informed consent prior to enrollment. 


\subsection{Statistical analysis}

The data were described statistically in terms of mean \pm standard deviation $( \pm \mathrm{SD})$, median and range, or frequencies (number of cases) and percentages, when appropriate. Comparison of numerical variables between the study groups was done using the student's $t$ test for independent samples. Within group comparisons of numerical variables were done using the paired t-test. The Chi-square test was performed to compare the categorical data. The exact test was used instead when the expected frequency was less than five. Correlations between the various variables were determined by using the Pearson moment correlation equation for the linear relationship between normally distributed variables, and Spearman's rank correlation equation was used for non-normal variables/non-linear monotonic relationships. The p-values that were less than 0.05 were considered to be statistically significant. All statistical calculations were done using the Statistical Package for the Social Science (SPSS), SPSS, Inc., Chicago, IL, USA), release 15 for Microsoft Windows.

\section{Results}

The study included 41 cases with uncontrolled CPOAG with coexisting cataracts. The ages of the patients were in the range of 43-67 with a mean of $54.8 \pm 5.3$. The gender distribution was $61 \%$ males and $39 \%$ females. The mean cup disc ratio (C:D ratio) was $0.7 \pm 0.09$ (Table 1). The mean visual field defect detected by Humphrey (mean deviation (MD)) was $13.9 \pm 2.7$ preoperatively, which improved in the first examination at three months to $12.6 \pm$ 2.6; then, it became stable until the end of the study, as evidenced by the fact that the values were 12.6 $\pm 2.6,12.6 \pm$ 2.6, 12.6 \pm 2.6 , and $12.6 \pm 2.6$ at $6,12,24$, and 36 months, respectively (Tables 1,2).

Table 1. Preoperative characteristics

\begin{tabular}{|l|l|l|}
\hline \multicolumn{2}{|l|}{ Age (year) } & $43-67(54.8 \pm 5.3)$ \\
\hline Gender & Male & $61 \%$ \\
\cline { 2 - 3 } & Female & $39 \%$ \\
\hline IOP & $23.8 \pm 1.8$ \\
\hline Log MAR & $0.12 \pm 0.06$ \\
\hline Visual Field MD & $13.9 \pm 2.7$ \\
\hline Anti-glaucoma drugs & $100 \%$ on 3 drugs \\
\hline CD Ratio & $0.7 \pm 0.9$ \\
\hline
\end{tabular}

Table 2. Post-operative characteristics

\begin{tabular}{|c|c|c|}
\hline \multirow{3}{*}{$\begin{array}{l}\text { VA } \\
\text { Scleral Pocket Height }\end{array}$} & \multicolumn{2}{|c|}{$0.9 \pm 0.07$} \\
\hline & $6 \mathrm{~m}$ & $0.56 \pm 0.1$ \\
\hline & $12 \mathrm{~m}$ & $0.58 \pm 0.1$ \\
\hline \multirow[t]{6}{*}{ IOP } & $1 \mathrm{~m}$ & $14.15 \pm 1.9$ \\
\hline & $3 \mathrm{~m}$ & $14.9 \pm 2.0$ \\
\hline & $6 \mathrm{~m}$ & $15.2 \pm 2.0$ \\
\hline & $12 \mathrm{~m}$ & $15.8 \pm 2.4$ \\
\hline & $24 \mathrm{~m}$ & $16.3 \pm 2.1$ \\
\hline & $36 \mathrm{~m}$ & $16.8 \pm 2.3$ \\
\hline \multirow[t]{5}{*}{ Visual field MD } & $3 \mathrm{~m}$ & $12.6 \pm 2.6$ \\
\hline & $6 \mathrm{~m}$ & $12.6 \pm 2.6$ \\
\hline & $12 \mathrm{~m}$ & $12.6 \pm 2.6$ \\
\hline & $24 \mathrm{~m}$ & $12.6 \pm 2.6$ \\
\hline & $36 \mathrm{~m}$ & $12.6 \pm 2.6$ \\
\hline \multirow[t]{3}{*}{ Anti-Glaucoma treatment } & \multicolumn{2}{|c|}{2 drugs $4.9 \%$} \\
\hline & \multicolumn{2}{|c|}{3 drugs $12.2 \%$} \\
\hline & \multicolumn{2}{|c|}{ Without treatment $82.9 \%$} \\
\hline
\end{tabular}

Best corrected $\log$ MAR visual acuity significantly improved from $0.12 \pm 0.06$ preoperatively to $0.9 \pm 0.07$ postoperativelly $(\mathrm{p}<0.001)$ (Tables 1,2$)$. The IOP decreased from $23.8 \pm 1.8$ preoperatively to $14.2 \pm 1.9,14.9 \pm$ $2.0,15.2 \pm 2.0,15.8 \pm 2.4,16.0 \pm 2.2,16.3 \pm 2.1,16.8 \pm 2.8$, and $16.8 \pm 2.3$ at $1,3,6,12,18,24,30$, and 36 months, respectively. The mean of IOP reduction was $9.6 \pm 2.7,8.80 \pm 2.8,8.51 \pm 2.8,7.90 \pm 3.0,7.68 \pm 3.0,7.41 \pm 2.8$, $6.93 \pm 3.1$, and $7.0 \pm 2.9$ at $1,3,6,12,18,24,30$, and 36 months, respectively (Tables 1,2). The mean height of the scleral pocket was $0.56 \pm 0.1$ and $0.58 \pm 0.1$ at 6 and 12 months, respectively. A significant correlation was found 
between the height of the scleral pocket and the reduction in the IOP, $p<0.001$. Subconjunctival bleb was found in 31 cases $(75 \%)$ (Table 2). All forty-one cases $(100 \%)$ were on three anti-glaucoma treatments preoperatively that decreased postoperatively to $2(4.9 \%)$ cases on 2 drugs, $5(12.2 \%)$ cases on three drugs, and $34(82.9 \%)$ without any anti-glaucoma treatment. The decrease of anti-glaucoma treatment was significant $(\mathrm{p}<0.001)$ (Tables 1,2$)$. The overall success rates were $97.5,95$, and $92.7 \%$ in the first, second, and third year, respectively. The overall success rate was $90 \%$ in the first year, which decreased to 85.3 and $78 \%$ in the second and third year, respectively. Qualified success was $7.5,10$, and $14.7 \%$ in the first, second, and third year, respectively. The failure rate was $2.5,5$, and $7.3 \%$ in the first, second, and third year, respectively (Table 3 ).

Table 3. Probability success rate

\begin{tabular}{|l|l|l|l|l|}
\hline Year & Overall success rate & Complete Success Rate & Qualified success rate & Failure Rate \\
\hline $1^{\text {st }}$ year & $97.5 \%$ & $90 \%$ & $7.5 \%$ & $2.5 \%$ \\
\hline $2^{\text {nd }}$ Year & $95 \%$ & $85.3 \%$ & $9.7 \%$ & $5.0 \%$ \\
\hline $3^{\text {rd }}$ year & $92.7 \%$ & $78 \%$ & $14.7 \%$ & $7.3 \%$ \\
\hline
\end{tabular}

\section{Discussion}

In patients with chronic primary open angle glaucoma (CPOAG) uncontrolled with medical treatment and with coexisting cataract, it is a sound thinking to go towards combined cataract and glaucoma surgeries in the same session. The optimal technique for management of glaucoma and cataract is in frequent change aiming at obtaining perfect results, shorter recovery time, and fewer complications (24). Deep sclerectomy aims at reducing IOP by facilitating filtration of aqueous humor into the intra-scleral filtering space through the filtering trabeculo-descemet's membrane. Part of the aqueous humor is redirected to the suprachoroidal and supraciliary spaces that may be absorbed through the uveo-scleral outflow pathway (9). Use of an implant during NPGS is thought to enhance success by providing a low pressure intra-scleral pocket between the external flap and trabecular meshwork, acting as a space maintainer during the time of maximal healing (25), but it may be too expensive to be used routinely with deep sclerectomy. In the current study, we tried to use the amniotic membrane as an adjunctive device for improvement of the results of deep sclerectomy in conjunction with phacoemulsification in CPOAG. Amniotic membrane implantation provides a group of tasks that might make it a highly-beneficial tool in glaucoma surgery, i.e., it provides good epithelization, provides good integration with the surrounding tissues, allows healing response, and suppresses TGF-B activity and poor immunogenicity. It acts as an anti-inflammatory, anti-proliferative, antifibrotic device (14). Amniotic membrane implantation was used by Sheiha et al. (15) in conjunction with MMC as an adjunctive maneuver for augmentation of the efficacy of trabeculectomy. The study included 37 eyes with refractory glaucoma at a high risk of failure, such as neovascular, pseudophakic, and prior failure cases. The study had a success rate of $93.7 \%$ at 6 months postoperatively in comparison to $60 \%$ success rate in patients who underwent trabeculectomy with MMC alone. The IOP decreased in that study from $45.6 \pm 12.7$ to $15.3 \pm 2.3 \mathrm{mmHg}$ in comparison to $21 \pm 3.8 \mathrm{mmHg}$ in trabeculectomy with MMC alone. In the current study, we tried to use MMC $(0.4 \mathrm{mg} / \mathrm{ml}$ for three minutes) in addition to amniotic membrane implantation in conjunction with deep sclerectomy to enhance the IOP reduction. Several authors tried to use antimetabolites, such as MMC, as an adjunctive treatment to enhance the effect of deep sclerectomy in IOP control by reducing the formation of scar tissue at the filtration site. In a 36-month follow-up study done by Kozobolis et al. (26) to compare deep sclerectomy augmented with MMC $(0.2 \mathrm{mg} / \mathrm{ml} / 2.5 \mathrm{~min})$ to deep sclerctomy without MMC the application of MMC was associated with improvement of qualified success rate from $72.5 \%$ without MMC to $95 \%$ with MMC application. The study included 68 eyes with CPOAG and exfoliation glaucoma that underwent deep sclerectomy with MMC $(0.4 \mathrm{mg} / \mathrm{ml}$ for two minutes $)$ and DSCI implant. The IOP decreased from $23 \pm 6$ and $25 \pm 8$ to $13 \pm 4$ and $11 \pm 4$ in groups 1 and 2, respectively. At 36 months, the success rate was $74 \%$. The success rate in our study was higher because we included CPOAG and pseudoexfolliation glaucoma as well as deep sclerectomy was done alone without phacoemulsification, which might have added an IOP-lowering effect in addition to that success rate was calculated as IOP is $<18 \mathrm{~mm} \mathrm{Hg}$ versus $<21$ $\mathrm{mmHg}$ in our current study. The authors detected that patients with pseudo exfoliation syndrome required goniopuncture more frequently than CPOAG patients despite MMC application (87\% versus $61 \%$, respectively). This was explained by the authors as the accumulation of pseudo exfoliation material and pigment deposition into the trabecular meshwork resulted in a decreased success rate. In the present study, we tried to investigate the effectiveness of combined phacoemulsification with deep sclerectomy augmented with MMC application in addition to amniotic membrane implantation in $\mathrm{CPOAG}$ cases with cataract. The mean IOP decreased from $23.8 \pm 1.8$ preoperatively to $16.8 \pm 2.3$ at the end of the study. All cases were on three anti-glaucoma treatments that decreased to $4.9 \%$ of cases on two drugs and 12.2 on three drugs at the end of the study. The overall success rate was $97.5,95$, and $92.7 \%$ in the first, second, and third year, respectively. The complete success rate was $90 \%$ in the first year, but 
it decreased to 85.3 and $78 \%$ in the second and third year, respectively. Qualified success was $7.5,10$, and $14.7 \%$ in the first, second, and third year, respectively. Failure was recorded as $2.5,5$, and $7.3 \%$ in the first, second, and third year, respectively. IOP reduction was sustained through the follow-up period. Our results coincided with those in a study done by Mokbel et al. (17), which was a comparative study of phacoemulsification-subscleral trabeculectomy versus phacoemulsification-deep sclerectomy with MMC in open angle glaucoma. The study included 40 chronic, open-angle glaucoma patients with senile cataracts. Half of the cases underwent phacoemulsification with subscleral trabeculectomy, and the other half received phacoemulsification with deep sclerectomy. Application of 0.4 $\mathrm{mg} / \mathrm{ml}$ of MMC was done in both groups. The cases were followed for one year. The mean preoperative IOP was $23.5 \pm 2.1$ and $24.1 \pm 1.5$ in groups 1 and 2, respectively, and, postoperatively, it became $14.1 \pm 5.4$ and $14.8 \pm 3.1$ in groups 1 and 2, respectively. The detected overall success rates were 90 and $95 \%$ after one year in gro ups 1 and 2, respectively. The study detected that 75 and $80 \%$ was the complete success rate in groups 1 and 2, respectively, while $15 \%$ was the qualified success in both groups. The higher success rate in our study may be explained by the use of amniotic membrane in addition to MMC application that was only used by Mokbel et al. in addition to high selection of only CPOAG cases in our study versus all types of open-angle glaucoma in their study.

The results of the current study also coincided with the results of a study done by Ye et al. (27) that detected a complete success rate $100 \%$ after 3 months that decreased to $90 \%$ at 6 months and to $76.7 \%$ at 12 months, but the incomplete success rate was $100 \%$ over the follow-up period. The subjects in the study underwent deep sclerectomy with $0.4 \mathrm{mg} / \mathrm{ml} \mathrm{MMC}$ application and amniotic membrane implantation only without cataract extraction. To the best of our knowledge, the current study is the first study to detect the effectiveness of deep sclerectomy augmented with both MMC and amniotic membrane in conjunction with phacoemulsification. Contrary to our results, Bilgin et al. (21), in a study comparing combined phacoemulsification with deep sclerectomy to deep sclerectomy alone, included 52 eyes with cataracts and primary open-angle glaucoma or pseudo exfoliation glaucoma in a 36-month follow-up period. The IOP was decreased from $23 \pm 7.8 \mathrm{mmHg}$ to $14 \pm 2.8 \mathrm{mmHg}$ in the deep sclerectomy group, while it was decreased from $23.5 \pm 5.1$ to $14.6 \pm 2.2 \mathrm{mmHg}$ in the group with combined phacoemulsification plus deep sclerectomy. The complete and qualified success rates were $65.3 \mathrm{nd} 88.4 \%$, respectively, for the phaco-NPD group and 73.1 and $92.3 \%$, respectively, for the NPD patients. The reason for the higher success rate in our study was the high selection of cases in our study, as we included only cases of CPOAG, but their study included cases of pseudoexfoliation glaucoma as well. Also MMC application in addition to amniotic membrane implantation increased complete and qualified success rate. A high rate of ND:YAG gonio-punctures appeared as a complementary procedure in most studies done on deep sclerectomy. It becomes necessary when the percolation of aqueous humor through the trabeculo-descmet's window appears insufficient. The gonio-pucture maneuver converts the glaucoma surgery from the non-penetrating into the penetrating type (22). The adjunctive use of gonio-puncture increases the success rate of non-penetrating deep sclerectomy. Rebolleda et al., in an attempt to analyze the effect of Descemet's membrane perforations to convert the deep sclerectomy to a trabeculectomy, reported that, in deep sclerectomy cases, it was necessary to convert $8.9 \%$ after 7 to 28 months of follow-up. IOP values were similar to those obtained in cases not needing perforation. However, their reported complications, although not serious, were significant, with hyphema, choroidal detachment, and fibrinous uveitis (28). In our current study, gonio-puncture was done in $3(7.3 \%)$ of cases with minimal complications that included only mild-to-moderate fibrinious reaction and hyphema that resolved spontaneously with medical treatment within one week.

The formation of filtering bleb is not a routine in non-penetrating glaucoma surgery; it was estimated by Stegmann et al. (29) as $5 \%$ of cases of viscocanalostomy. In our study the bleb appeared in $75 \%$ of cases, which corresponded with the observation of Mermoud (30) who observed bleb formation in up to $50 \%$ of eyes after viscocanalostomy. The cause of that observation may be explained by the double anti-fibrotic action that was achieved by MMC application in addition to amniotic membrane implantation under the scleral flap that prevented healing of the flap with the scleral bed. According to the literature, ultrasound biomicroscopy (UBM) accredit measurement of the dimensions including the height of the scleral pocket of aqueous as well as the thickness of trabeculo-descmet's membrane $(31,32)$. In the current study, the height of the scleral pocket was $0.56 \pm 0.1,0.58 \pm 0.1$ at 6 and12 months, respectively, which was greater than the height in a study done by Contrera et al. (33), i.e., 0.36 and 0.39, respectively. The study was done undergoing deep sclerectomy with implantation of acrylic implant in conjunction with phacoemulsification and IOL implantation in three cases that underwent HEMA implant. A significant correlation was found in the current study between the height of the aqueous lake and the IOP reduction $\mathrm{p}<$ 0.001.These results coincide with the study done by Aptel et al. (34) that included 15 cases underwent deep sclerectomy with ologen implant using UBM and OCT, lower IOP was correlated with bleb height and thickness of trabeculo-descmet's membrane based on UBM study. Lower IOP was correlated with the size of sub -conjunctival 
bleb as well as thin wall of the bleb and low bleb reflectivity detected by anterior segment OCT. The results partially coincided with the study done by El-saied et al. that concluded the surface area not only the height of the bleb correlates with the decrease of IOP after deep sclerectomy (35). The study concluded that the intra-scleral bleb surface area was directly correlated to the degree of IOP reduction. The study involved deep sclerectomy with MMC application alone without adjunctive implants. Contrary to our study, Khairy et al. (36) included 22 eyes that had deep sclerectomy without the use of anti-metabolite or scleral implant and examined them by UBM. UBM evaluated the presence and maximum length as well as height of the intra scleral space, the minimum thickness of residual trabeculo-descemet's membrane. They concluded that the surgical outcome was not associated with the variability of UBM values of the surgical area.

In the current study, the mean visual field defect (mean deviation (MD)) was $13.9 \pm 2.7$ preoperatively that improved in the first examination done at three months to $12.6 \pm 2.6$ and then became stable until the end of the study as it was $12.6 \pm 2.6,12.6 \pm 2.6,12.6 \pm 2.6$, and $12.6 \pm 2.6$ at $6,12,24$, and 36 months, respectively. This coincided with the study by Chen et al. (37) that concluded that in eyes with mild to moderate glaucoma damage the mean deviation often improve after cataract extraction. Contrary to our results, Carrillo et al. (38) concluded that, although there are changes in the effect on the visual field after cataract extraction, they were negligible as a group, and they decided the high variability among different cases. Phacoemulsification plus deep sclerectomy can be used in cases of uncontrolled, primary, open-angle glaucoma with cataracts. The success rate can be augmented for a large scale by using an adjunctive MMC application, and the addition of amniotic membrane implantation increases the probability of success and the long-term viability of IOP control. It provides an adjunctive safety measure against unwanted hypotony in advanced glaucoma. The limitations of this study included the small number of cases as well as the selective type of patients of primary open angle glaucoma. Further studies can evaluate the effect of this procedure in other types of open-angle glaucoma.

\section{Conclusions}

Amniotic membrane implantation in conjunction with $\mathrm{MMC}$ application may contribute an alternative to expensive implants in deep sclerectomy combined with phacoemulsification. It can be used safely in advanced CPOAG patients.

\section{Acknowledgments:}

The author did not receive any grant from any entity to conduct this research.

\section{Conflict of Interest:}

There is no conflict of interest to be declared.

\section{References}

1) Resnikoff S, Pascolini D, Etyal 'ale D, Kocur I, Pararajasegram R, Pokharel GP, et al. Global data on visual impairment in the year 2002. Bull World Health Organ. 2004; 82(110): 844-51. PMID: 15640920, PMCID: PMC2623053.

2) Budenz DL, Gedde SJ. New options for combined cataract and glaucoma surgery. Curr Opin Ophthalmol. 2014; 25(2): 141-7. doi: 10.1097/ICU.0000000000000027. PMID: 24389806.

3) Rosdahl JA, Chen TC. Combined cataract and glaucoma surgeries: Traditional and new combinations. Int Ophthalmol Clin. 2010; 50(1): 95-106. doi: 10.1097/IIO.0b013e3181c5563a. PMID: 20057299.

4) Casson RJ, Salmon JF. Combined surgery in the treatment of patients with cataract and primary open angle glaucoma. J Cataract Refract Surg. 2001; 27(110): 1845-63. doi: 10.1016/s0886-3350(01)01127-0. PMID: 11709261.

5) Law SK, Nguyen AM, Coleman AL, Caprioli J. Severe loss of central vision in patients with advanced glaucoma undergoing trabeculectomy. Arch Ophthalmol. 2007; 125(8): 1044-50. doi: 10.1001/archopht.125.8.1044. PMID: 17698750.

6) Mermoud A, Schnyder CC. Non-penetrating filtering surgery in glaucoma. Curr Opin Ophthalmol. 2000; 11: 151-7. doi: 10.1097/00055735-200004000-00015. PMID: 10848223.

7) Yuen NS. Early results of modified non penetrating deep sclerectomy and phacoemulsification in the treatment of open angle glaucoma and cataract. Eur J Ophthalmol. 2009; 19(1): 72-9. PMID: 19123152.

8) Mermoud A, Schnyder CC, Sickenberg M, Chiou AG, Hediguer SE, Faggioni R. Comparison of deep sclerectomy with collagen implant and trabeculectomy in open angle glaucoma. J Cataract Refract surg. 1999; (2593): 323-31. doi: 10.1016/S0886-3350(99)80079-0. 
9) Vaudaux J, Mermoud A. Aqueous dynamics after deep sclerectomy: ex-vivo study. Ophthalm pract. 1998; 16: 204-9.

10) Shaarawy T, Nguyen C, Schnyder C, Mermoud A. Comparative study between deep sclerectomy with and without collagen implant: Long-term follow up. Br J Ophthalmol. 2004; 88: 95-8. doi: 10.1136/bjo.88.1.95.

11) Dahan E, Ravinet E, Ben-Simon GJ, Mermoud A. Comparison of the efficacy and longevity of nonpenetrating glaucoma surgery with and without a new non absorbable hydrophilic implant. Ophthalmic Surg. Lasers Imaging. 2003; 34: 457-63. PMID: 14620748.

12) Shaarawy T, Mansuri K, Schnyder C, Ravinet E, Achache F, Mermoud A. Long-term results of deep sclerectomy with collagen implant. J Cataract Refract Surg. 2004; 30: 1225-31. doi: 10.1016/j.jcrs.2003.10.035. PMID: 15177596.

13) Jochinm E, Weirman 1, Matthiessen N, Wagnefeld L, Galambos N, Richard G. Comparison between absorbable and non-absorbable scleral implants in deep sclerectomy (T flux and SK-Gel) -Mid-term results. IOVS. 2007; 48(13): 817.

14) Willoch CM, Nicolaissen B. Amniotic shielded trabeculectomy. Acta Ophthalmolgica Scand. 2003; 658-9.

15) Sheha H, Kheirkhah A, Taha H. Amniotic membrane transplantation with mitomycin $\mathrm{C}$ for refractory glaucoma. J Glaucoma. 2008; 17(4): 303-7. doi: 10.1097/IJG.0b013e31815c3a47. PMID: 18552616.

16) Ollikanien ML, Puustarvi Tj, Rekonen PK, Usitalo HM, Terasvirta ME. Mitomycin C-augmented deep sclerectomy in primary open angle glaucoma and exfoliation glaucoma: a three-year prospective study. Acta Ophthalmol. 2011; 809(6): 548-55. doi: 10.1111/j.1755-3768.2009.01772.x. PMID: 19925527.

17) Mokbel TH, Ghanem AA, Moawad AI, Nafie EM, Nematallah EH. Comparative study of phacoemulsification-subscleral trabeculectomy versus phacoemulsification-deepsclerectomy. Saudi Journal ophthalmol. 2009; 23(3): 189-96. doi: 10.1016/j.sjopt.2009.10.008. PMID: 23960859, PMCID: PMC3729327.

18) Kim NR, Lee H, Lee ES, Kim JH, Hong S, Je Seong G, et al. Influence of cataract on time domain and spectral domain optical coherence tomography retinal nerve fiber layer measurements. 2012; 21(2): 116-22.

19) Rehman siddiqui MA, Khairy HA, Azuara-Blanco A. Effect of cataract extraction on SITA perimetery in patients with glaucoma. J Glaucoma. 2007; 16: 205-8. doi: 10.1097/IJG.0b013e31802dfc35. PMID: 17473731 .

20) Anand S, Anand N. Combined phacoemulsification and deep sclerectomy (PDS)with intraoperative mitomycin C (MMC) augmentation. Eye. 2008; 22(8): 1040-9. doi: 10.1038/sj.eye.6702833. PMID: 17464299.

21) Bilgin G, Karakurt A, Saricaoglu MS. Combined non-penetrating deep sclerectomy with phacoemulsification versus non-penetrating deep sclerectomy alone. Semin Ophthalmol. 2014; 29(3): 14650. doi: 10.3109/08820538.2013.874466. PMID: 24506739.

22) Di Stato S, Taverniti L, Genitti G, Marangolo L, Aiello A, Giuffré L, et al. Combined phacoemulsification and deep sclerectomy versus phacoemulsification and trabeculectomy. Acta Ophthalmol Scand Suppl. 2000; 232: 59-60.

23) Munoz Negrete FJ, Rebolleda G, Noval S. Non-Penetrating deep sclerectomy combined with phacoemulsification. Results and complications. Arch soc Esp Oftalmol. 2003; 78(9): 499-506. PMID: 14517737.

24) Vass C, Menapace R. Surgical strategies in patients with combined cataract and glaucoma. Curr Opin Ophthalmol. 2004; 15(1): 61-6. doi: 10.1097/00055735-200402000-00012. PMID: 14743022.

25) Cheng JW, Cheng SW, Cai JP, Li Y, Wei RL. Systemic overview the efficacy of non penetrating glaucoma surgery in the treatment of open angle glaucoma. Med Sci Monit. 2011; 17(7): 155-63. doi: 10.12659/MSM.881840. PMID: 21709645, PMCID: PMC3539577.

26) KozobolisVP, ChristodoulakisEV, TazanakisN, ZacharopoulousI, Pallikaris IG. Primary deep sclerectomy versus primary deep sclerectomy with the use of mitomycin $\mathrm{C}$ in primary open angle glaucoma. J Glaucoma. 2002; 11: 287-93. doi: 10.1097/00061198-200208000-00003.

27) Ye W, Sun J, Zhong Y. Implication of non -perforating deep sclerectomy with amniotic membrane implantation for primary open angle glaucoma .Yan ke xue Bao eye science. 2002; 18: 76-9.

28) Rebolleda G, Muñoz-Negrete FJ. Phacoemulsification-deep sclerotomy converted to phacotrabeculectomy. J Cataract Refract Surg. 2004; 30(7): 1597-8. doi: 10.1016/j.jcrs.2004.04.030. PMID: 15210250.

29) Segman R, Pienaar A, Miller D. Viscocanalostomy for open angle glaucoma in black African patients. J Cataract Refract Surg. 1999; 25: 316-22. doi: 10.1016/S0886-3350(99)80078-9.

30) Mermoud A. Sinusotomy and deep sclerectomy. Eye. 2000; 14: 531-5. doi: 10.1038/eye.2000.140. PMID: 11026983. 
31) Kazakova D, Roters S, Schnyder CC, Achache F, Jonescu-Cuypers C, Mermoud A, et al .Ultrasound biomicroscopy images: Long term results after deep sclerectomy with collagen implant. Grafes Arch Clin Exp Ophthalmol. 2002; 240: 918-23. doi: 10.1007/s00417-002-0567-7. PMID: 12486514.

32) Marchini G, Marraffa M, Brunelli C, Morbio R, Bonomi L. Ultrasound biomicroscopy and intraocular pressure lowering mechanisms of deep sclerectomy with reticulated hyalouronic acid implant. J Cataract Refract Surg. 2001; 27: 507-17. doi: 10.1016/S0886-3350(00)00857-9.

33) Contreras I, Noval S, Munoz-Negrete FJ, Rebolled G, Garcia -Feijoo J, De La Camara J. Ultrasound Biomicroscopy in deep sclerectomy with a new acrylic implant. Arch Soc Esp Oftalmol. 2006; 81: 445-50. PMID: 16933168.

34) Aptel F, Dumas S, Denis P. Ultrasound biomicroscopy and optical coherence tomography imaging of filtering bleb after deep sclerectomy with collagen implant. Eur J Ophthalmol. 2009; 19(2): 223-30. PMID: 19253238.

35) El-Saied HM, Abdelhakim AS, ELdaly MA, Fouad PH. One year follow up of deep sclerectomy using ultrasound biomicroscopy. J Egyptian Ophthalmoliogical Society. 2014; 107(2): 82-5. doi: 10.4103/20900686.140642 .

36) Khairy HA, Atta HR, Green FD, Van Der Hoek J, Azuara-Blanco. Ultrasound biomicroscopy in deep sclerectomy. Eye. 2005; 19: 555-60. doi: 10.1038/sj.eye.6701558. PMID: 15761488.

37) Chen PP, Budenz DL. The effects of cataract extraction on visual field of eyes with chronic open angle glaucoma. Am J Ophthalmol. 1998; 125(30): 325-33).

38) Carrillio MM, Artes PH, Nicolela MT, LeBlanc RP, Chauhan BC. Effect of cataract extraction on the visual fields of patients with glaucoma. Arch Ophthalmol. 2005; 123(70): 929-32. 